Dr. Ferriman: Would it be wrong to say that each member should take 2 or 3 journals and tell his colleagues which papers in them are worth their attention?

Dr. Mattingly: No, I am sure that this is one funotion of a Journal Club. But it is equally important to take 1 or 2 papers and discuss them oritically.

Dr. C. T. ANDREws : At Truro we have had a Journal Club for General and Chest Physicians for two or three years. We invite to this our Medioal Registrars and any other member of the junior staff who may be working for the M.R.C.P. diploma. We do not ask the Chest Physicians to review chest journals as we think there is a danger that they will involve us in a discussion of the minutiae of pulmonary function. Our monthly meetings last two hours and there is an average attendance of about 12. Anyone not attending regularly is taken off the mailing list. This arrangement has worked very successfully.

DR. W. J. STOKES: Although there is obviously a place for specialised and depantmental Journal Clubs, at Stoke Mandeville Hospital the Journal Club includes staff at all levels and meets every Monday at 1.20 p.m. in the Nuffield Library. Coffee is served. Under a permanent and erudite chairman, four speakers come prepared to present a special article or two from their allotted journal for periods up to ten minutes, allowing time for discussion. Numbers attending average ten to twelve, although perhaps twenty belong.

We feel that junior staff should realise how little of the current literature anyone of us is capable of reading, and should be encouraged to present their contribution, perhaps under the guidance of a chief or registrar.

The Journal Club would seem a valuable part of hospital routine; and although attendance cannot be made compulsory, we have recently appealed that some pressure be made through consultants that their respective firms attend whenever possible.

Those who complain concerning the contents of the library or of the postgraduate programmes only have themselves to blame! They are well represented on the Postgraduate Advisory Committee, are repeatedly asked for suggestions by the Tutor, and should complete the questionnaires which they receive through the post.

DR. Rinsler (St. Stephen's): The maximum beneffif from Journal Clubs accrues to the person presenting such a paper. I find the ones I present are alway. clear in my memory as opposed to those I listes? to presented by others, because one is very carefu to anticipate criticism. Housemen derive most beneff from the critical evaluation of a paper, which thes are quite unused to doing themselves. Experienced people should guide them.

Dr. Mattingly: There is a place for a club wheret you have everyone. I do not think that we should expect our pre-registration people to spend too muct time reading journals at this stage. I found textbook more helpful in this period myself. Is the exercise. primarily an educational experience for junior stafs or is it education for oneself?

DR. LEATHER (Plymouth): I have been involved i ip Journal Clubs for 10 years and find them very valuable. We get six or eight junior members attendu ing weekly meetings, in University terms, from 9-10 a.m. on Mondays. Attendance is less good in the evening.

Mr. T. L. Schofield (Bath): I have also had $1 \bar{g}$ years experience. We have departmental clubsconsultant and registrars-but invite S.H.O.s, wh $\vec{\theta}$ are taking higher exams. The meetings are mire successful in the atmosphere of a consultant's home. We regard this as training for junior staff. Jourfis are allocated, especially the important ones, to peow 1 s takling exams. A discussion often develops that binsts far into the night-for instance, one that centred $\bar{D}$ the last leader in the Lancet on gastro-duodena haemorrhage.

DR. PAulley: I very much agree with the lasi speaker about involving the junior staff, but pres registration housemen must not be excluded-this may be their first chance of learning to use the library. They must be helped to evaluate materiat for themselves. We have weekly meetings, discuss sing only one paper-the discussion is the mos valuable part. My experience is that pre-registration. men find this most valuable and their contributions are often the most stimulating. We have made it a parade and the head of the department must be there ibperson.

\title{
INTERDEPARTMENTAL TEACHING
}

\author{
Bernard Lennox, M.D., Ph.D., F.R.C.P.(G), F.C.Path., M.R.C.P. \\ Reader in Pathology, Western Infirmary, University of Glasgow.
}

I HAVE been given twice as long as my fellowspeakers and I have assumed that this is an invitation to try and tackle my subject in some depth. I am going therefore to say very little about such matters as the minutiae of management of clinico-pathological conferences. It is not that they do not matter: they do, but they vary greatly with local circumstances, and or N $^{2}$ the whole it is best to work out the details op the spot. I shall come back to a few practicas points at the end, but I want to spend most op my time dealing with the background, with the ambient circumstances which make good interdepartmental teaching possible. I am welf 
aware that in doing so I am teaching whole groves of my grandparents to aspirate the proverbial ova, but I think it's worth trying.

I have, I suppose, been picked on, as many people here might equally have been, because 1 had once a good deal to do with the Hammersmith clinico-pathological conferences, and they seem to be reganded still as one of the most successful examples of the interdepartmental genre in the country. I did, of course, leave Hammersmith ten years ago, but at least I suppose I have learnt something additional since then.

In Glasgow during these last ten years I have watched the establishment of several sorts of interdepartmental teaching. Some have succeeded, some have flopped. In addition, there has been the new Glasgow curriculum with its integrated year, which involves a good deal of interdepartmental teaching of one sort or another, and though that is all undergraduate there has been plenty to learn from it. There have been our Postgraduate Medicine TV programmes, most of which have been interdepartmental to some extent, and that has proved a very stern school indeed. In all these various attempts, even the less successful ones, there has been a good deal of food for thought. I would like to state here and now my main conclusion-it is a crashingly obvious one, but it's worth stating and worth repeating-all interdepartmental teaching ultimately boils itself down in the end to a dialogue between two people, and (whatever Chekhov can get away with, and even Pinter at times) you can only have a proper dialogue between two people if each is interested in what the other has to say.

\section{Personality in Teaching}

There are basically after all only three kinds of teaching - teaching with no personality, teaching with one personality, and teaching with two personalities or more.

Teaching without personality, provided it is done with reasonable efficiency, is the necessary bread-and-butter for getting over the facts: at the very worst it makes a change from the books. But it does not much matter whether one teacher is concerned or several. Even if a group of teachers come from several departments, if they don't communicate with each other and each is concerned only with recital of the facts and textbook dogma, the only kind of team they form is a relay team; and the chief result of their acting in relays is to exhaust the unfortunate audience all the quicker. That comment is perhaps particularly relevant to the less imaginatively organized type of integrated course: but I think we ought to agree for our present purpose that merely getting people to talk in relays on separate aspects of one topic is not good interdepartmental teaching.

Teaching by one personality doesn't concern us here. Provided the effort doesn't distort either the personality itself or the facts, it remains probably the most efficient and economical of all modes of teaching. Which gives me an excuse to make one additional point in passing. I think most teaching should still be one-man, the only dialogue being that between the teacher and his audience. It's simple and undistracting, and it's cheap. We cannot after all abandon departmental teaching altogether, any more than we can abandon all departments. A hedge between keeps friendships green, as the saying is, provided it is not too high a hedge. Teaching by a team really acting as a team costs far more in trouble and man-hours, not only in the time spent in actual teaching but in the organization beforehand, and it is very apt to develop irrelevant elements that distract from the learning process. It makes for variety, and there are some things it can teach better than anything else canespecially attitudes-but too much of it stales the variety and is a waste of resources. Having made that point however, I hasten to say that: I know nowhere in this country where it is used too much and few places where it is used enough.

\section{Finding the Right Teacher}

What one needs then in the first place for good interdepartmental teaching is a minimum of two people from different departments who are really prepared to talk to each other. And they are not likely to talk profitably in public if they cannot talk in private.

It matters remarkably little what sort of people they are. They don't for instance need to be of equal seniority. Some of the best dialogues occur between youth bursting with the latest news and age intent on discovering whether the news is true. It only needs that youth should know what he is talking about, and age not have lost his curiosity-two things unfortunately not universal.

Now good dialogues cannot be repeated very often. One can play-act a little, but not for ever. Of course one can expect an unending source of variety in the actual case material used as a basis for the more practical meetings, but it is a mistake to rely too much on this. Beauty lies in the eye of the beholder, and two 
men enjoying bandying soft words and hard arguments over a sebaceous cyst or the X-ray of a Pott's fracture can be better company and better teaching than two monomaniacs holding forth on the greatest rarity you can imagine.

The simplest way of achieving variety is to vary one's team. And this in its turn means one must have a reasonable supply of people genuinely interested in the work of other departments. Which is the rub. It were a good fish if it were but caught. Everyone in theory is interested in what goes on elsewhere. The kind of people who attend a mixed conference like this are usually the kind of people with some general interests. But in practice, in most places, the fraction of the staff who are interested enough, and confident enough - the things go together-to be able to ask real well-thought-out questions outside their own sphere, and go on doing it once a week for a term or two, is strictly limited.

Most people, as we all know, think departmentally, and in consequence teach departmentally-which is not for a moment to deny that they may be very good at that and quite indispensable in that role. Good interdepartmental teaching, however, can only be achieved in a school or hospital in which there are at least a substantial number of people who think interdepartmentally. Good fish, as I said earlier, if they can be caught. But need they be caught? The replacement of hunting by agriculture and stock-raising is generally thought to be a forward step in the evolution of man. Can we not become cultivators, and artificially encourage the breed? I think we can-here at least are a few thoughts on the subject.

\section{The Undergraduate Contribution}

Obviously one should begin with the young idea and encourage it in undergraduates. Of course one sets them a good example if one can-like shepherd, like sheep-but this is a circular argument: where do you get the teachers to set the example in the first place? And it's not altogether as simple as it sounds. Genuine discussion between their teachers at a level that really interests their teachers is apt to go over the heads of too many of them. Surgical C.P.C.'s at a simple "what's this lump" level are possible quite early, for instance, but medical C.P.C.'s-real useful discussions on the case I mean, not just excuses for dogmatic exposition-are not much use till late in the course and something of a risk even then. Most use is a spell of integrated teaching
- some parts of it at least are likely to work out as demonstrations that the interdisciplinary approach does sometimes pay. And it pays too a useful bonus in an effect on the teachers. It ensures that a whole lot of teachers, from several departments and of all levels of seniority, have their heads thoroughly knocked together and have to think in company about what each of them teaches and why. This is very good for them.

One other thing about integrated teaching is that it must lead to an integrated examination, and joining together to make a single examination is another very good way of enforcing co-operation. Joint examinations are great educators, especially of the examiners $-I$ know I keep up-to-date with bacteriology almost wholly through the Third M.B. vivas. And here again, if $I$ might ride a private hobby horse, could I put in a plea for multiple-choice exam papers? You can learn a little about a department's teaching from one of its ordinary essay question papers, but not much, unless you read the answers also. Work through another department's objective paper, and you'll find yourself with a pretty clear idea of what they teach and which things they think importantand usually with a most distressing realization of how much has changed since you last thoughto you knew anything about it.

\section{Clinical Meetings in the Hospital}

Next there are meetings. One can judge the health of a hospital I think very fairly from its staff medical meetings. I mean particularly the Grand Rounds or Clinical Meetings or Saturday Forums or what have you-a regular meeting where cases are shown by every department to every department for every department. They are of course first class postgraduate teaching in themselves. But they ought not to be regarded as primarily that: in fact any attempt to play to the audience can ruin the play. The staff must show things for each other's delight and instruction: they themselves are the most important students.

These meetings are so valuable an institution that enormous care should be taken to keep them running sweetly. They should be held in working hours and be regarded as work. The hall they are held in and its equipment should be of the best, and the hospital administration should regard the provision of this as a major priority.

Responsible seniors should go to all possible pains to see the right cases are available and 
that they are presented properly. They should do the presentation sometimes themselves, just to show how it ought to be done, but they must let their juniors have most of the limelight: only, when the juniors are really junior, they must ensure that they have all possible help (and coaching if necessary) to make certain the stuff is properly put over. Senior people in the audience have a particularly difficult task: they must be there as often as possible or their juniors will drift away after them: above all they must stay awake, both physically and mentally. They must speak when they have something to say that no one else can or will, but they must not hog the floor. The opposite of Parliamentary procedure should prevail, the young back-benchers being given priority and the Privy Councillors bringing up the rear.

I have seen enough of such meetings in different places, and with the widest differences in format, to know that most places can do them exceedingly well when they try. I would repeat the view that such meetings have an absolutely key role in any postgraduate programme. (I heard only yesterday of one relevant fact: there is one medical school in this country, of excellent general standing but singular in two particulars - it runs no general clinical meeting, and it plays next to no part in the postgraduate programme in its area). They're good postgraduate teaching in themselves, and the best of correctives to the formalization and departmentalization of so much postgraduate teaching: but more important, they teach the teachers. Moreover, what better place to pick your team of teachers?

\section{Other Factors}

There are many other things I could mention. Such as the value of joint research projects as educators, and the value of unified libraries where the other man's journals are just round the corner from your own. Odd things like the deplorable design of dining rooms, which often seem to be arranged especially to encourage eating in departmental cliques-or to drive people out of the hospital so that they do not meet anyone. But perhaps especially worth mentioning are the virtues of simple propinquity. It's always easier to love one's neighbour than the man in the next street. Wide open spaces are all very well, but they make for isolation: the best hospitals to work in are big but compact buildings with good communications where visiting is easy. It seems to us now self-evident that a medical school and its main hospital should be part of a single building unit. Thirty or forty years ago that doesn't seem to have been so obvious. Too many people nowadays don't seem to recognise that, whatever the site problems it may raise, the same applies to a medical school and its university-they need to be next door to each other. And if we recognise that good postgraduate teaching can rarely be based on a single hospital, that's just one more argument for the hospital groupand by group I don't mean an administrative figment, I mean a real physical cluster.

Which takes me a long way away from the original idea of two people talking together. But the diversion is not altogether unjustified. The quality of their talk will always be partly a product of themselves, but also partly a product of their environment, and in making this environment we must consider the macroclimate as well as the micro-climate.

\section{Subjects and Objects}

I've left myself very little time to talk abouêิ the actual sessions, but I'm unrepentant abouk this. It's men, not houses, that build the city? and if you have the right people the rest is easy. But let me say a few things.

One useful classification will serve to start with. One can discuss a subject, or one can discuss an object. In the first, two or more people discuss the management of anuria, or the causes of cancer, or some such subject. In the second, they take an object, a patientif you won't mind my calling a patient an object for the sake of argument-or an X-ray or a specimen, or something of the sort. What I think is the most dangerous kind of interdepartmental teaching is that which relies solely on its subject-the sort of panel discussion for instance in which four or five experts are put on a platform together and told to discuss chronic bronchitis, or computers in medicine. They may improvise something, or they may have a chairman who can impose a pattern, or some genius in the audience may ask the right questions. For major occasions, as for instance a TV programme, one can script it, but it is extraordinary how hard it is to write a good script for one, and extraordinary how bad they can be without a script. As an art form panel discussions of that type have as much shape as an art student's sweater-I mean the male variety-and are commonly to

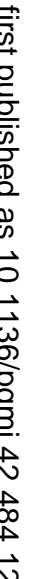


just about an equal degree knitted from pure wool.

I have little doubt that the safest and usually the best sessions of interdepartment teaching are those that have an object to centre around. If one must have a panel discussion, it is usually best to turn it into the safe type by the bull-baiting technique-setting up the most argumentative member of the team to talk about his own point of view, and then letting the others attack him. That is after all what keeps a conference like this sweet-we treat each paper as an object and kick it around for a while. But the only really universally successful kinds of medical interdepartmental teaching - and by universally successful I don't mean that they can never fail, only that it seems possible to make them work almost anywhere - are the grand round and the clinicopathological conference, and these hinge entirely on the discussion of the best of objects for the purpose, a case.

\section{The C.P.C.}

I've already said something about Grand Rounds. I thought I could usefully finish by a word or two about the Hammersmith C.P.C.'s. Perhaps I view them through rose coloured spectacles - "that free and friendly conference that we have known of old," as Cassius might have called them-but I think they were good. They still are, but I speak of them as I knew them. I shall stick to the medical ones, which are better known, but the surgical ones could be just as good.

There was no real secret about them except hard work, willingness to argue, and good relations between departments. A vital flying start was given by the presence of clinicians at daily post mortem demonstrations: that meant one could choose the best cases at once-no frantic search at the last minute for cases where by good luck the clinicians still had the notes and the pathologist still had the organs. The standard of work-up on both sides was always very high: on both sides the heads of departments frequently presented the case themselves and set an exceedingly high standard of care in doing so. Two practical points-first, a roneo'd history summary, which is a great aid to concentration from the audience. Second, what was shown was always if possible the actual object-the actual organs, the actual microscope slides: the second-hand of the lantern slide was avoided if possible. But the great thing, then as now, was the discussion after the demonstration, when the departments let down their hair and really tried to milk each other dry of ideas and information. That is real interdepartmental teaching.

There is an interesting comparison with the older rival show at the M.G.H. They have a perennial gimmick in the visiting clinician invited to make a diagnosis on the history. It must be good fun, but, reading the accounts, one can see snags. The history often has to be distorted to make the game possible. It over-emphasizes the importance of the diagnosis, which is often only a very minor part of the interest of the case. And the role of the pathologist is reduced to the pontifical one of popping up at the end and pronouncing the right answer-a totally false image of his function. You must always argue with your: pathologist, whether or not he is right. Gimmicks are fine if you can avoid taking them too seriously. Hammersmith has at least demonstrated that in this matter you can do just as well without any gimmicks at all.

Another thing about Hammersmith of course is that they are professionals. For most of the rest of us, postgraduate teaching is really only a sideline. There is a lesson there, of course. But I do not want to follow that argument. I would reiterate that there is no difficulty at all about interdepartmental teaching. You just need a community of the right people, and if you do not have one you must make one. 


\title{
DISCUSSION
}

Dr. Forgacs (Woolwich) found that in his area the C.P.C. was the most suocessful form of meeting; care was taken in choosing the moderator. This was also a way of bringing in clinidians at other hospitals. MR. M. R. Williams said that at Canterbury, veteninary and dental surgeons took part in some meetings which were therefore interprofessional and very successful.

Professor Hewer (Bristol) had found that these meetings in the University Department could only be held at 5.15 which was not a good time for general practitioners, in spite of this there was a few who came fairly regularly. His hospital also held a meeting at 8.15 p.m. on one day a month to review the cause of death of everyone dying in the previous month. An interdepantmental committee seleoted four cases for special discussion. Registrars and Senior House Officers were present but general practitioners were not invited. He considered that clinical pathological conferences were most valuable and believed it should be possible for them to be held even in small hospitals.

Professor SMart (Newcastle) said that in their new integrated curriculum there were two years of interdepantmental teaching. It was very important to have active participation and questioning by all members of the audience, whatever their ages.

DR. LENNOX in reply to a question, thought that the effort needed for publication was too great to be worthwhile, but obviously some people read these discussions with enjoyment.

\section{MEDICAL EDUCATIONAL ADVISORY SERVICE}

\author{
N. C. Manley-CoOper \\ Smith, Kline and French Laboratories Ltd.
}

As a normal rule my Company feel it preferable to provide some specific "Service" of benefit in this field rather than to allocate sums of money which tend to be dissipated over a wide area. In the past Smith Kline and French have provided such services as closed circuit colour television, inter-continental link programmes, specialised medical films, tape recordings, videotaping facilities etc. A very considerable expertise in all forms of instructional technique and audiovisual equipment and its use has therefore been acquired and the benefit of this experience might be of significant value to individual schools and medical centres.

Much more use could be made of modern techniques of instruction which tend to communicate the content of lectures to far wider audiences, thus saving considerable effort on the part of eminent lectures and tending to alleviate the constant problem of shortage of good teachers. One of the basic problems is some sort of course in instructional techniques which are of great value in teaching the teachers in the various modern techniques of instruction such as group discussions, case history presentations, and syndicated learning, many of which would appear to be eminently suitable for Medical Centres and which would tend to bring out the practical experience of individual teachers rather than their theoretical knowledge. Considerable benefit could be achieved by all concerned by the organisation of such courses perhaps on a regional basis.

I am grateful to the Chairman and Dr. Ellis for all the support that Smith, Kline and French have received in sponsoring the Conference both from the Medical School and from ASME.

$A D D E N D U M$ : In view of the many enquiries received since the Postgraduate Clinical Tutors Meeting held in Birmingham in November Smith Kline and French Laboratories Limited are pleased to announce that they are setting up a Medical Educational Advisory Service which it is hoped will cover many aspects of educational problems confronting those concerned in the organisation of programmes for Postgraduate Medical Centres. For further details please write to Mr. N. C. Manley-Cooper, Head of Medical Educational Services, Smith Kline and French Laboratories Limited, Welwyn Garden City, Hertfordshire. 